\title{
British Association for the Study of the Liver
}

The 1993 Spring Meeting of the British Association for the Study of the Liver was held at the Royal Free Hospital, London on 25-26 February 1993. The 17 abstracts selected for presentation by the Programme Committee are printed below.

Hepatitis $\mathbf{C}$ virus genotypes: an investigation
of type specific differences in geographic origin and disease

G DUSHEIKO, H WEISS, D BROWN, S-W CHAN, P-L YAP, S SHERLOCK, N MCINTYRE, P SIMMONDS (Royal Free Hospital School of Medicine, London, and University of Edinburgh) It has become important to clarify whether genotypes of hepatitis $\mathrm{C}$ virus correlate with pathogenicity, infectivity, response to antiviral treatment, and geographic clustering. We have analysed the pattern of nucleotide sequence variability in the 5 prime non-coding region ( $5^{\prime} \mathrm{NCR}$ ) by restricting enzymes to analyse the distribution of HCV genotypes in 80 patients with chronic hepatitis C. Genotypes were correlated with demographical, clinical, and histological features. Biopsies were coded as (1) mild or moderate chronic hepatitis without cirrhosis or (2) severe chronic hepatitis, cirrhosis or hepatocellular carcinoma. There were 55 men and 25 women, mean age 47.5 years. Thirty nine patients were infected with type 1 , 10 with type 2 , eight with type 3 , a further 21 were infected with a new distinct HCV type provisionally termed type 4 , and two were infected with an as yet uncharacterised type (U). There was a significant association between geographical origin and genotype Types 1, 2 or 3 were found in patients from the United Kingdom, southern Europe, Asia, Africa, and South America. Seventeen of 21 type 4 genotype isolates, however, were from Middle Eastern patients compared with 2/39 type 1 isolates $(\mathrm{p}<\cdot 005$, Odds ratio $15 \cdot 7)$. Conversely, 18/20 (90\%) Middle Eastern patients had type $4 \mathrm{HCV} v 2 / 20$ with type 1 ( $p<\cdot 005$, Odds ratio 9). There was no significant difference between the mean ages or mean serum aminotransferase concentrations between the various types. Types $1,2,3$, and $U$ were found in patients with both (1) mild to moderate disease, or (2) severe disease. Twenty two of 31 patients with type 1 who had liver biopsies had severe chronic hepatitis, cirrhosis or hepatocellular carcinoma histologically, compared with $9 / 31$ who had mild or moderate chronic hepatitis without cirrhosis $(p=0.04$, Odds ratio $2 \cdot 5$ ). There was little definite relation between viral genotypes and response to alpha interferon treatment. Our data suggest that different HCV genotypes can be encountered in both mild and severe disease. There is a significant geographical clustering of type 4 in the Middle Eastern area. The clinical significance and prognostic importance of these genotypes may require prolonged follow up studies.

A quantitative comparison of circulating hepatitis $C$ virus during ribavirin and alpha interferon treatment of chronic hepatitis $\mathbf{C}$

S RASSAM, J WILBER, N THOMPSON, A RIDLEYDASH, $M$ URDEA, P NEUWALD, S SHERLOCK, N MCINTYRE, G DUSHEIKo (Royal Free Hospital School of Medicine, London, and Chiron Corporation, Califormia, United States) Quanti- tation of circulating hepatitis $\mathrm{C}$ virus $(\mathrm{HCV})$ is important for understanding mechanisms of antiviral treatment. We have evaluated the effect of ribavirin in 28 patients and compared it with the effect of interferon by quantitation of HCV.

Twenty eight ribavirin treated patients, seven patients who responded to alpha interferon, and seven untreated controls, were studied. Ribavirin treated patients received $1 \mathrm{~g}$ daily for 4-12 months (mean 7). HCV RNA in serum was measured in 14 of the ribavirin treated patients by a branched (bDNA) signal amplification assay to quantitate HCV RNA. Selected samples were tested by nested PCR, amplifying the 5'NCR of HCV.

One hundred and seventy nine samples were assayed and several patterns were seen. Three of seven ribavirin patients had normal alanine aminotransferase activities (ALT) and HCV RNA was below the level of detection. Four of seven patients had normal ALT but HCV RNA remained detectable as it did in $6 / 7$ nonresponders and 6/7 untreated controls. Most of the untreated controls had periods when viral RNA was undetectable. One patient with abnormal ALT had undetectable RNA. The mean number of genome equivalents per $\mathrm{ml}$ was $3 \times 10^{5}$ before treatment $v 2.73 \times 10^{5}$ in months 2,3 , and 4 (pooled, excluding six negative samples). The mean genone equivalent $/ \mathrm{ml}$ in the untreated patients was $5 \cdot 27 \times 10^{5}$. In all seven interferon responsive patients, HCV RNA became negative. This did not preclude later relapse, however.

Quantitative polymerase chain reaction measurement of HCV RNA indicates that ribavirin has 'virustatic' effect in hepatitis C; alpha interferon is more effective in diminishing circulating $\mathrm{HCV}$. Quantitation of $\mathrm{HCV}$ RNA in serum provides a rapid diagnostic test of viral inhibition during antiviral treatment, and will improve our understanding of the mechanisms of antiviral treatment.

\section{Viral hepatitis in intravenous drug misusers} dying from heroin overdose

E A B MCCRUDEN, K J HILLAN, B BATCHELOR, J C CLARK, R N M MACSWEEN (Institute of Virology, Department of Pathology, and the Departmen of Forensic Medicine, University of Glasgow, Glasgow) Serum samples from 21 (17M/4F) intravenous drug misusers (IVDMs) dying from heroin overdose in Glasgow in 1985-89 were tested for $\mathrm{HBsAg}$, antiHBc, antiHBs, antiHIV, second generation antiHCV EIA (all Abbott), second generation immunoblot (RIBA-2-Chiron), and for antidelta (Murex) Necropsy liver specimens were examined histologically.

Four serum samples were $\mathrm{HBsAg}$ positive: of these none had antiHBc IgM, one was $\mathrm{HBeAg}$ positive, and three were antidelta positive including the one that was $\mathrm{HBeAg}$ positive. Markers of past hepatitis $B$ infection were present in 12 , absent in one while in four there was insufficient serum for testing. All 21 serum samples were positive by antiHCV EIA and confirmed by RIBA-2 with differences in the patterns of reactivity to the different antigens. All 21 were antiHIV negative. Two cases had established cirrhosis proved on histological examination and in one there was fibrous scarring. These cases were the only three infected with HBV, HepCV, and HDV. Of the remaining cases, 14 had moderate hepatitic features, without significant fibrosis and four had only a mild portal infiltrate.

It is concluded that: (1) hepatitis C is present in a very high proportion of IVDMs who die of heroin overdose in Glasgow; (2) severe liver disease was seen only in the IVDMs with chronic $\mathrm{HBV}$ and delta virus infections.

Factors predicting a response to IFN $\alpha$ treatment of chronic hepatitis $B$ infection

A P CATTERALL, R KING, P GUARASCIO, R H T LOKE, J Y N LAU, H M DANIELS, G VISCO, G J $M$ ALEXANDER, I M MURRAY-LYON, ROGER WILliams (King's College Hospital, Charing Cross Hospital, London, and Ospedale Spallanzani, Rome, Italy) To determine those variables existing before treatment are predictive of a response to IFN $\alpha$ therapy, we have assessed 111 patients from three centres (Charing Cross Hospital, London; King's College Hospital, London, and Ospedale Spallanzani, Rome, Italy) with chronic hepatitis B virus (HBV) infection who received IFN $\alpha$ alone or in combination with acyclovir or after a short course of corticosteroids.

Overall, $42 / 111$ (38\%) of patients responded to IFN $\alpha$ treatment. Eighteen different pretreatment variables were analysed with univariate analysis then by stepwise logistic regression. With stepwise logistic regression, only lower basal HBV DNA values and a negative HIV antibody status were significantly associated with a response to IFN $\alpha$ treatment $(p<0.001$ and $p=0.016$ respectively). Of the patients who had HBV, DNA values below $30 \mathrm{pg} / 40 \mu \mathrm{l}, 23 / 32 \quad(72 \%)$ responded compared with $19 / 78(24 \%)$ of responders with values above $30 \mathrm{pg} / 40 \mu \mathrm{l}$.

These results suggest that a subgroup of HBV positive individuals are more suitable for IFN $\alpha$ treatment.

Primary biliary cirrhosis (PBC) specific M2 autoantibodies in patients with recurrent urinary tract infection using an ELISA and purified pyruvate dehydrogenase

P BUTLER, J M T HAMILTON-MILLER, H BAUM, A K BURROUGHS (Hepatobiliary and Liver Trans plantation Unit, and Department of Microbiology, Royal Free Hospital, Hampstead, London, and Division of Life Sciences, King's College, Campden Hill Road, London) We have recently shown, using SDS-PAGE of beef heart mitochondria and western blotting, the presence of low titre anti-mitochondrial antibodies (AMA) in a group of patients with a history of recurrent urinary tract infection (UTI) but no evidence of liver disease (Butler et al, $\mathcal{F}$ Hepatol 
(in press)). The most common reactivity was against $\mathrm{E} 2$ alone (in $52 \%$ of patients), the $74 \mathrm{Kd}$ component of pyruvate dehydrogenase (PDH) - the major autoantigen of PBC. The results have been questioned as being due to nonspecific binding or naturally occurring antimitochondrial antibodies (NOMA). Thus, using an ELISA based on purified PDH we detected and quantified anti-PDH antibodies in four study groups: normal controls $(n=28)$, PBCs selected for anti-74 Kd positivity $(n=48)$, chronic liver disease (CLD), controls $(n=30)$, recurrent UTIs $(n=43)$. Values $>2$ $\mathrm{SD}$ above the mean for normal controls were considered positive. ELISA was positive in all of the PBC patients (100\%), one of the normal controls (4\%), five CLD patients (17\%), and 23 recurrent UTI patients $(54 \%-\mathrm{p}<0.002$ for recurrent UTI groups $v$ controls and $\mathrm{p}<\mathbf{0 . 0 5}$ chronic liver disease.

This confirmation of true AMA reactivity in recurrent UTI patients with no liver disease means that there is no non-specific binding of antibodies on western blots and that reactivity is not due to NOMA's. Importantly, CLD patients who are known to have a high prevalence of antibodies to gram negative bacteria had a much lower incidence of anti-PDH antibodies compared with the recurrent UTI group, so that previous bacteraemas common in chronic liver disease patients does not explain our finding.

We conclude that not only the nature of the organism but also the route of infection provides a basis for our hypothesis for antigenic mimicry in PBC and may explain the pathogenesis of $M 2$ specific antibodies in this condition (Burroughs et al Nature 1992; 358: 377-8).

T-cell response to the major human mitochondrial autoantigen in primary biliary cirrhosis

D E J JONES, J M HALES, J M PALMER, S J YEAMAN, A G DIAMOND, M F BASSENDINE (Departments of Medicine, and Biochemistry and Genetics, University of Newcastle-upon-Tyne) Antimitochondrial antibodies in primary biliary cirrhosis (PBC) react with components of the 2-oxo acid dehydrogenase complexes; the immunodominant B-cell epitope is the lipoyl domain of the E2 polypeptide of pyruvate dehyrogenase complex (PDC). Less is known about the role of T-cells in the pathogenesis of PBC. The aim of this study was to examine the proliferative response of peripheral blood mononuclear cells (PBMC) from PBC patients and controls to human PDC.

Twenty nine PBC patients and 26 controls (18 healthy and eight with chronic liver disease) were studied. PBMC were cultured for six days with human PDC (purified from heart muscle obtained at organ allograft) and proliferation measured by ${ }^{3} \mathrm{H}$ thymidine incorporation. Responses to PDC were compared with those to tetanus toxoid.

Twenty three of $29 \mathrm{PBC}$ patients showed a proliferative response to $\mathrm{PDC}$ (stimulation index $>2$ ) compared with 4/26 controls $(p<0.005)$. In contrast proliferative responses to tetanus toxoid showed no significant difference between PBC patients and controls (20/29 PBC patients $v$ 19/26 controls). We concluded: (1) in contrast with previous in vitro studies in PBC using mitogens the $\mathrm{T}$-cell response to a recall antigen (tetanus toxoid) is not impaired (2) this is the first demonstration of a T-cel proliferative response to human PDC in PBC. The lack of response in controls suggests that this is a disease specific phenomenon.
Adhesion molecule expression in primary sclerosing cholangitis (PSC)

S L BLOOM, K FLEMING, R W CHAPMAN (Departments of Gastroenterology and Histopathology, Fohn Radcliffe Hospital, Oxford) Adhesion molecules are important in facilitating cell contact in $\mathrm{T}$ cell mediated cytoxicity. There are conflicting reports in published works regarding ICAM-1 expression in hepatic inflammatory disorders. ${ }^{12}$ This study aimed to report on the distribution of adhesion molecules in primary sclerosing cholangitis (PSC) compared with disease and normal controls.

Frozen section liver biopsy specimen from nine patients with PSC were studied. Four were histological stage 1 or 2, five were histological stage 3 or 4 . Controls included biopsy specimens from patients with primary biliary cirrhosis (PBC) $(n=3)$, large duct obstruction $(n=3)$, chronic active hepatitis (CAH) $(n=3)$, alcoholic liver disease $(n=3)$, and histologically normal biopsy specimens $(n=3)$. Sections were stained with antibodies to ICAM-1, LFA-1, VCAM, E-Selectin, and HLA-DR. Detection was by both immunoperoxidase and APAAP. Staining of proliferating ductiles, small and large ducts, endothelium, Kupffer cells, and inflammatory infiltrate was scored by an experienced histopathologist ignorant of diagnosis and antibodies.

ICAM-1 was seen on proliferating ductules and bile ducts in 3/9 PSC biopsy specimens, all histological stage 3 . Two biopsy specimens (stage 1 or 2) were focally positive for ICAM-1 on bile ducts but negative on proliferating ductiles. ICAM-1 was negative on normal bile ducts and present in $2 / 12$ disease controls. ICAM-1 was seen on endothelium and sinusoidal lining cells in normal, disease control, and PSC patients with no detectable difference between groups. Seven of nine PSC biopsy specimens were positive for HLA-DR, compared with $2 / 12$ disease controls. There was no staining detected for E-Selectin or VCAM. LFA-1 stained infiltrating inflammatory cells in both PSC and disease controls.

Only $5 / 9$ biopsy specimens with PSC showed ICAM-1 expression, in two of these being confined to focal positivity on larger ducts. Bile ductiles were positive for ICAM-1 only in advanced disease. This suggests that ICAM-1 expression may be secondary to prior events inducing inflammation rather than of pathogenic importance. Previous reports of ICAM-1 prevalence may have been biased towards end stage, pre-transplantation biopsy specimens.

1 Adams DH, Hubscher S, et al. Hepatology 1991; 14: 426-31.

2 Hultcrantz R, Broome U, et al. Hepatology 1991; 14: $63 \mathrm{~A}$

Positive association between gamma/delta $T$ lymphocytes and autoimmune liver diseases

E B G MARTINS, R W CHAPMAN, $K$ A FLEMING (Department of Gastroenterology and Nuffield Department of Pathology and Bacteriology, Fohn Radcliffe Hospital, Oxford) Gamma/delta $(\gamma / \delta)$ T-lymphocytes are associated with some autoimmune diseases, for example rheumatoid arthritis and coeliac disease. To investigate a possible association between $\gamma / \delta \mathrm{T}$-lympocytes and autoimmune liver diseases, we have analysed portal tract and peripheral blood lymphocytes in patients with primary sclerosing cholangitis (PSC), autoimmune hepatitis (AIH), and primary biliary cirrhosis (PBC).

Portal $\gamma / \delta$ T-lymphocytes were analysed using immunohistochemistry on frozen liver biopsy specimens from seven PSC, four AIH, and 10 PBC patients, and compared with six normal controls. Peripheral blood lymphocytes isolated from PSC (18 patients), AIH (16), PBC (25), and controls (19) were analysed using flow cytometry.

The number of portal $\gamma / \delta \mathrm{T}$-lymphocytes was higher in PSC (mean (SEM)) $(6 \cdot 14(0 \cdot 86)$, $\mathrm{p}=0.001)$, AIH $(9.75(2.72), \mathrm{p}=0.006)$, and PBC $(5 \cdot 20(1 \cdot 28), \mathrm{p}=0.039)$ when compared with controls $(1 \cdot 17(0 \cdot 75))$. The proportion of peripheral blood T-cells with the $\gamma / \delta$ receptor was also increased in patients with PSC (mean $(\mathrm{SEM}))(9.17(3.08), \mathrm{p}=0.021)$, and $\mathrm{AIH}$ $(6.26 \%(0.99), \mathrm{p}=0.01)$ but not in PBC $(3.86 \%$ $(0.68), \mathrm{p}>0.05)$ when compared with controls $(3 \cdot 44(0 \cdot 44))$.

Portal and peripheral blood $\gamma / \delta$ Tlymphocytes are increased in PSC and $\mathrm{AIH}$; in contrast with PBC there is an increase only in portal $\gamma / \delta$ lymphocytes. These findings suggest an association between $\gamma / \delta \mathrm{T}$-lymphocytes and autoimmune liver diseases. The aetiopathogenic role of these $\mathrm{T}$-lymphocytes merits further investigation.

DNA polymorphisms in the complement $\mathrm{C4}$ genes in patients with autoimmune hepatitis

D G DOHERTY, P T DONALDSON, J A UNDERHILL, A G DEMAINE, A L W F EDDLESTON, ROGER WILlIAMS (Institute of Liver Studies and Department of Medicine, King's College School of Medicine and Dentistry, London) Patients with autoimmune hepatitis (AIH) have low levels of complement component $\mathrm{C} 4$ and increased frequencies of $\mathrm{C} 4$ null alleles when compared with the normal population. To evaluate the molecular basis of these null alleles we have analysed DNA polymorphism in the C4 genes in 68 white patients with $\mathrm{AIH}$ and 95 matched controls using restriction fragment length polymorphism analysis. A DNA deletion covering the C4A gene and the closely-linked cytochrome P450 21-hydroxylase A (CYP21A) pseudogene was found to be present in $50 \%$ of patients compared with $23 \cdot 2 \%$ of controls $(p<0 \cdot 005$, relative risk $=3 \cdot 3)$. Complete $C 4 A$ deficiency, determined by homozygosity for this deletion was associated with a relative risk of $18 \cdot 1$ for $\mathrm{AIH}$, being present in $16.2 \%$ compared with $1 \cdot 1 \%$ of controls $(p<0 \cdot 005)$. No $\mathrm{C} 4 \mathrm{~B}$ gene deletions were found. Of the 34 patients who had at least one C4A gene deletion, $97 \%$ possessed HLA-DR3 and DR52a, $91 \%$ had $\mathrm{B} 8$, and $79 \%$ had $\mathrm{Al}$, indicating that this deletion generally cosegregates with the A1-B8-DR3-DR52a haplotype of the major histocompatibility complex.

Primary HLA DRw52a and Dw2 associations in a primary sclerosing cholangitis (PSC) population

W Z MEHAL, B P WORDSWORTH, K A FLEMING, R W CHAPMAN (Department of Gastroenterology, Department of Rhematology, Nuffield Department of Pathology, Fohn Radcliffe Hospital, Oxford) The frequency of alleles encoding DRw52a, DR3, DR2, and Dw2 was significantly increased in a British population of 71 PSC, with the DR 3 and DR2 associations being secondary to DRw52a and Dw2. This was not confirmed in a Swedish sample of 21 PSC. To examine the question of which allele within the two linked pairs DR3, DRw52a and DR2, Dw2 is providing the primary association we genotyped, 49 PSC and 64 normal white controls from Oxfordshire. 
Formalin-fixed paraffin-embedded liver biopsy specimen tissues were dewaxed, desiccated, and digested with proteinase $\mathrm{K}$. A sequence common to all HLA DR loci was amplified, blotted onto nylon filters, and sequentially hybridised with $\mathrm{P}^{32}$ end labelled probes specific for HLA DR2, Dw2, DR3, DRw52a, and DR4.

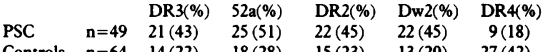

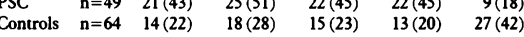

We conclude that in our population of PSC: (a) DRw52a has a stronger association than DR3 (DRw52a X ${ }^{2}$ 6.17, DR3 X $X^{2}$ 5·7); (b) Dw2 has a stronger association than DR2 (Dw2 $\mathrm{X}^{2}$ $7 \cdot 8, \mathrm{DR} 2 \mathrm{X}^{2} 5 \cdot 8$ ). Furthermore, DR4 is significantly reduced in PSC (DR4 X $\left.{ }^{2} 7 \cdot 2\right)$, but not when the displacement effect of DRw52a is corrected for.

Regulation of lipocyte derived $\alpha 2$-macroglobulin and $72 \mathrm{kDa}$ type IV collagenase/ gelatinase by Kupffer cell medium and dexamethasone

C A KAWSER, P J WINWOOD, J P IREDALE, M J P ARTHUR (University Medicine Group, University of Southampton, Southampton) Degradation of the normal hepatic matrix, which is rich in type IV collagen, leads to hepatocellular dysfunction and activation of lipocytes to a fibrogenic phenotype. Both $72 \mathrm{kDa}$ type IV collagenase/gelatinase $(72 \mathrm{kDa} \mathrm{C} / \mathrm{G})$ and $\alpha 2$-macroglobulin $(\alpha 2 \mathrm{M}$, a scavenger of $72 \mathrm{kDa} \mathrm{C/G}$ ) are secreted by activated lipocytes; their ratio being likely to influence the outcome of liver injury. The aim of this study was to determine the relative secretion of $\alpha 2 \mathrm{M}$ and $72 \mathrm{kDa} \mathrm{C} / \mathrm{G}$ activity by cultured rat lipocytes in response to well characterised modifiers of inflammation in the liver.

Lipocytes and Kupffer cells were prepared by pronase/collagenase digestion of normal rat liver followed by density gradient centrifugation (nycodenz) and centrifugal elutriation. Serum free lipocyte conditioned medium was analysed for $\alpha 2 M$ by ELISA and type IV C/G activity by ${ }^{14} \mathrm{C}$ gelatin degradation and gelatin substrate SDS-PAGE.

Exposure of lipocytes to Kupffer cell conditioned medium (KCCM) caused a significant increase in $\alpha 2 M$ secretion ( $p<0.05$, Wilcoxon) but did not affect $72 \mathrm{kDa}$ gelatinase release. Dexamethasone, in combination with KCCM, caused a consistent but small further increase in $\alpha 2 M$ secretion $(p<0.05)$ and a significant decrease in $72 \mathrm{kDa} \mathrm{C} / \mathrm{G}$ activity $(\mathrm{p}<0.05)$, which seems to be independent of the effect of $\alpha 2 \mathrm{M}$ activity.

These data indicate differential regulation of $72 \mathrm{kDa}$ and its inhibitors in lipocytes. Suppression of $72 \mathrm{kDa}$ C/G activity by dexamethasone may represent a significant anti-inflammatory action of corticosteroids.

Regulation of Kupffer cell derived $95 \mathrm{kDa}$ type IV collagenase/gelatinase; a mediator of liver injury

P J WINWOOD, C A KAWSER, M J P ARTHUR (University Medicine Group, University of Southampton, Southampton) Kupffer cells, in common with other macrophages, secrete 95 $\mathrm{kDa}$ type IV collagenase/gelatinase. This enzyme, which degrades gelatin, types III, IV, and $\mathrm{V}$ collagens, may assist cell migration and proliferation in sites of injury in addition to having a role in matrix remodelling. As a consequence of destruction of the normal hepatic matrix, however, it may also promote liver injury and fibrosis. In this study we have investigated regulation of type IV collagenase/ gelatinase release by rat Kupffer cells in culture.

Kupffer cells were isolated from normal rat liver by pronase/collagenase perfusion and purified by density gradient centrifugation and centrifugal elutriation. Release of gelatinase activity in response to known activators of Kupffer cell functions was analysed in serum free media, after 5-7 days in culture by gelatin substrate SDS-PAGE and ${ }^{14} \mathrm{C}$ gelatin degradation.

Kupffer cells exposed to endotoxin or zymosan (yeast particles) for 24 hours consistently released increased $95 \mathrm{kDa}$ gelatinase activity (median increase $7 \cdot 1$ and 3.89 fold respectively, $\mathrm{p}<0.05$, Wilcoxon). Exposure to IL-1 $(300$ and $30 \mathrm{U} / \mathrm{ml}), \mathrm{TNF} \alpha(3000 \mathrm{U} / \mathrm{ml})$ and TGF $\beta_{1}(100 \mathrm{U} / \mathrm{ml})$ for $2,4,8$, and 24 hours elicited no significant change in released gelatinase activity and did not modulate the response to endotoxin or zymosan over a 24 hour period.

These results show that injurious Kupffer cell stimuli cause increased release of $95 \mathrm{kDa}$ type IV collagenase/gelatinase and support a role for this enzyme in liver injury. The absence of a response to cytokines supports the view that activation of Kupffer cell functions is specific to the stimulus.

Growth hormone and insulin resistance in cirrhosis

E SHMUELI, M STEWART, K G M M ALBERTI, C O RECORD (Royal Victoria Infirmary, University of Newcastle upon Tyne, Newcastle upon Tyne) Cirrhosis is characterised by paradoxical growth hormone secretion in response to glucose and insulin infusion. To ascertain if this abnormality contributes to insulin resistance, euglycaemic hyperinsulinaemic glucose clamps were performed on six patients with cirrhosis and six normal controls. Each subject underwent two clamps, a control clamp, and a clamp with somatostatin $(250 \mu \mathrm{g} / \mathrm{hr})$ together wth insulin and glucagon replacement. In the control clamp growth hormone levels were considerably higher in the patients with cirrhosis $(6.1(0.4)$ v $0.5(0.4) \mathrm{mu} / \mathrm{l}, \mathrm{p}<0.02)$ and glucose uptake considerably lower $(3.29(0.56)$ v $9.52(1.14) \mathrm{mg} / \mathrm{kg} / \mathrm{min}, \mathrm{p}<0.001)$. Indirect calorimetry indicated that the defect was accounted for by lower non-oxidative glucose disposal $(1.23(0.45) v 6.00(0.73), \mathrm{p}<0.001)$. Peripheral glucose uptake exemplified by forearm glucose uptake $(0.27(0.04) v 1.22(0.42)$ $\mathrm{mg} / 100 \mathrm{ml} / \mathrm{min}, \mathrm{p}<0.02)$, and calculated insulin sensitivity (24 (8) $v 114(20) \mu \mathrm{l} / \mathrm{kg} / \mathrm{min}$ per $\mathrm{mu} / \mathrm{l})$ were particularly diminished. Somatostatin suppressed growth hormone levels $(6 \cdot 1(1 \cdot 2)$ to $1.2(0.4) \mathrm{mu} / \mathrm{l}, \mathrm{p}<0.05)$, however, no significant changes occurred in whole body glucose uptake $(3.29(0.56) v 3.01$ $(0.54) \mathrm{mg} / \mathrm{kg} / \mathrm{min})$, forearm glucose uptake $(0.27(0.04) v 0.30(0.01) \mathrm{mg} / 100 \mathrm{ml} / \mathrm{min})$ or insulin sensitivity (24 (8) $v 35(10) \mu \mathrm{l} / \mathrm{kg} / \mathrm{min}$ per $\mathrm{mu} / \mathrm{l}, \mathrm{p}=0 \cdot 42$ ). We conclude that abnormal growth hormone secretion is not responsible for the peripheral insulin resistance of cirrhosis.

Alphafetoprotein variants in hepatocellular carcinoma and benign liver disease

L J BURDITT, M M JOHNSON, P J JOHNSON, ROGER WILliams (Institute of Liver Studies, King's College Hospital and King's College School of
Medicine and Dentistry, London) A significant proportion of patients with hepatocellular carcinoma (HCC) have abnormally raised levels of alphafetoprotein (AFP). Serum levels of AFP, however, may be significantly raised, between $50-350 \mathrm{ng} / \mathrm{ml}$, in benign hepatic diseases. Consequently a high serum AFP in patients with liver disease is not on its own an indication of HCC. We have developed a test for AFP variants using isoelectric focusing of serum from patients with $\mathrm{HCC}$ and benign hepatic diseases.

Serum samples $(2 \mu \mathrm{l})$ were focused in 0.4 mm thick agarose gels containing Pharmalyte ampholytes $\mathrm{pH} 4 \cdot 5-5 \cdot 4$. After capillary transfer to nitrocellulose AFP bands were detected using a rabbit anti-human AFP antibody. Serum samples from 17 patients with HCC, 13 with cirrhosis, three with fulminant liver failure, and six with chronic active hepatitis (CAH) all had one AFP band in common with pI 4.9. This band was also seen in serum samples from three clinically normal pregnant women. Serum from patients with established HCC showed one or two additional bands with more alkaline pI of 4.95 and $5 \cdot 05$. One or both of these bands was found in $94 \%$ of HCC patients tested. Five of the six CAH patients had a second band but with a more acidic $\mathrm{pI}$ of $4 \cdot 85$. Serial samples from a patient who initially presented with micronodular cirrhosis and after 18 months was diagnosed as $\mathrm{HCC}$, showed a gradual increase in intensity of the AFP band pI 4.95 characteristic of HCC

This technique should prove useful in screening serum samples from patients with various liver diseases who have significantly raised AFP (above $30 \mathrm{ng} / \mathrm{ml}$ ).

Hepatocyte growth factor mRNA detected in normal and fulminant liver by ribonuclease protection assay

P M HARRISON, A ACKRILL, A BOMFORD, C GOVE, F FARZANEH, ROGER WILLIAMS (Molecular Medicine Unit and Institute of Liver Studies, King's College School of Medicine and Dentistry, London) Hepatocyte growth factor (HGF) is a potent mitogen for mature hepatocytes and is regarded as the major hepatotrophic factor initiating liver regeneration following liver damage or resection. In fulminant hepatic failure (FHF), serum HGF protein levels are high, although the site of HGF production is unknown. After toxic injury, rat hepatic HGF mRNA levels increase three to fourfold. Therefore, we compared the expression of HGF mRNA in patients with FHF (tissue obtained at orthotopic liver transplantation) with that in unused donor grafts. Total RNA was extracted by the method of Chomczynski and $10 \mu \mathrm{g}$ analysed by ribonuclease protection assay. The HGF probe was a ${ }^{32} \mathrm{P}$-labelled $404 \mathrm{nt}$ antisense RNA transcribed in vitro. The template contained a portion of the HGF cDNA (nts 801 to 1468, Nakamura) amplified from normal liver by the polymerase chain reaction. The protection of ribosomal protein S14 RNA was used to control for input RNA. Low but comparable levels of HGF mRNA transcripts were detected in diseased and control specimens. These data argue in favour of an endocrine rather than paracrine mechanism of HGFstimulated liver growth in FHF

Increased lipid peroxidation in hepatorenal syndrome

K MOORE, J MORROW, J AWAD, G MARINI, ROGER WILLIAMS, L J ROBERTS II (Department of 
Clinical Pharmacology at Royal Postgraduate Medical School, London, Vanderbilt University, Nashville, USA, and Institute of Liver Studies, King's College School of Medicine and Dentistry, London) Hepatorenal syndrome (HRS) is caused by a reduction of both renal blood flow, and the glomerular capillary ultrafiltration coefficient $\left(k_{f}\right)$. Several vasoactive mediators have been implicated in its pathogenesis, including endothelin-1, leukotrienes, and prostanoids. The formation of these mediators may be increased by products of lipid peroxidation. We recently described a series of prostaglandin $F_{2}$ compounds ( $F_{2}$-isoprostanes formed through non-enzymic free-radical catalysed lipid peroxidation of arachidonic acid. One of these compounds, 8-epi-PGF ${ }_{2 \alpha}$, is also a potent renal vasoconstrictor, and severa studies have shown that its formation is a good marker of lipid peroxidation in vivo.

We have measured plasma levels of 8-epi$\mathrm{PGF}_{2 \alpha}$ (GCMS) in normal controls $(\mathrm{n}=12)$, compensated liver disease (CLD, $\mathrm{n}=6)$, decompensated liver disease (DLD, defined as ascites, bilirubin $>150 \mu M$ or INR $>2, n=6$ ) chronic renal failure (CRF, $n=4)$, and HRS $(n=6)$. Plasma levels in HRS were considerably higher $(113(28 \cdot 7) \mathrm{pg} / \mathrm{ml})$ compared with normal controls $(19 \cdot 0(7) \mathrm{pg} / \mathrm{ml}), \mathrm{CLD}(20 \cdot 2(4 \cdot 1) \mathrm{pg} /$ $\mathrm{ml})$, DLD $(21 \cdot 8(4 \cdot 0) \mathrm{pg} / \mathrm{ml})$, or CRF $(23.3$ $(3.5) \mathrm{pg} / \mathrm{ml})(\mathrm{p}<0.01)$. These results indicate that there is increased lipid peroxidation in hepatorenal syndrome. The underlying mechanism for this is unknown but may include endotoxaemia, or circulating activated inflammatory cells. Increased 8-epi-PGF ${ }_{2 \alpha}$ may also affect renal function if generated locally, but its functional significance is, at present, unknown. These data provide a rationale for further studies on the role of lipid peroxidation in the cause of hepatorenal syndrome.

$S$-Adenosylmethionine improves hepatic function during liver perfusion after sequential cold and warm ischaemic injury

J B DUNNE, M DAVENPORT, ROGER WILLIAMS, J $M$ TREDGER (Institute of Liver Studies and Department of Surgery, King's College Hospital and School of Medicine and Dentistry, London) $S$ Adenosylmethionine (SAMe) has proved beneficial in the treatment of cholestasis and in preventing experimental hepatotoxicity. We have studied its effects in reducing experimental preservation injury during sequential periods of cold ischaemia ( $24 \mathrm{~h}$ storage in University of Wisconsin solution [UW] at $4^{\circ} \mathrm{C}$ ) and warm ischaemia $\left(20 \mathrm{~min}\right.$ at $\left.37^{\circ} \mathrm{C}\right)$ [CI+ WI]. SAMe was given to male Lewis rats $(\mathrm{n}=7)$ 16-18 $\mathrm{h}$ before hepatectomy, included in the $\mathrm{UW}$, and added as a bolus to the perfusate just before reperfusion. $\mathrm{CI}+\mathrm{WI}(\mathrm{n}=6)$ irreversibly impaired haemodynamics with median liver blood flow, oxygen delivery, oxygen consumption, and oxygen extraction ratio $62 \%, 53 \%$, $142 \%$, and $260 \%$ respectively of control values $(\mathrm{n}=11)$ at $30 \mathrm{~min}$, but restored towards normal by SAMe in all cases: median $90 \%, 88 \%, 120 \%$, and $130 \%$ of control. SAMe also improved bile production (median $12.3 v 2.3 \mathrm{mg} / \mathrm{g} / \mathrm{h}$ at 15 min), total glucose release $(900 v 1440 \mathrm{mmol} /$ g.h) and acid production $(0.122 v 0.189 \mathrm{mmol} /$ g.h), but had no apparent benefit to parenchymal or endothelial cell damage.

We conclude that SAMe reduced metabolic injury resulting from $\mathrm{CI}+\mathrm{WI}$ as judged by bile flow, acid production, and glucose release. SAMe was also shown to be a novel potent agent for the improvement of haemodynamic function after ischaemic damage. 